\title{
A Forest Science Effective Research Supervision in the Faculty Of Forestry, Universiti Putra Malaysia
}

\author{
Kamaruzaman Jusoff \\ Forest Geospatial Information \& Survey Lab \\ Lebuh Silikon \\ Faculty of Forestry \\ Universiti Putra Malaysia \\ Serdang 43400 Selangor, Malaysia
}

Tel: 60-8946-7176_E-mail: kamaruz@putra.upm.edu.my, kamaruz@aeroscan.com.my

The research is financed by Universiti Putra Malaysia (Sponsoring information)

\begin{abstract}
At least historically, undergraduate research supervision has predominantly been seen as part of the basic research function of academic staff. In many fields of study, success in research requires not only sophisticated experimental and analytical skills, but good mentoring and managerial skills as well. This paper presents an observational case study and perception based on the author's true experiences exploring the most effective supervision of undergraduate students in the Faculty of Forestry, Universiti Putra Malaysia (UPM). Due to the need of a highly calibre first class honours undergraduates for the future pool of postgraduates and top notch academia in the Faculty and in UPM, the aim of this paper is therefore to provide a good practice guideline for supervision of undergraduates final year project reports/theses to ensure consistency of approach for staff and students across the faculty and university. Key topics covered include building an effective undergraduate final year project/theses supervisory relationship, negotiating expectations, providing good communication and feedback and providing motivation and guidance to them. Personal interviews of undergraduates' perceptions of their supervision as they undertake their final year research projects were presented. Students reported that only a select few of their supervisors were supportive and sympathetic to their needs. Only a few of the Faculty supervisors adopted the role of resource person, directing undergraduates to references and contacts, discussing ideas and work undertaken. Only a few students had considerable freedom in the conduct of their final year project work. They were not able to choose their own research topic and supervisor but most determined the pace at which they worked. Some appeared to cope well with the autonomous role of a junior researcher while some commented on difficulties. Though the majority of students were given considerable freedom in their research the results of the observation indicated some differences amongst supervisors.
\end{abstract}

Keywords: supervision, forestry science, undergraduate, research, theses

\section{Introduction}

Knowing what an undergraduate student can expect from an effective supervision in terms of support is vital when a student starts the research project/theses module. It may not be particularly easy for an undergraduate student to forge a relationship with a member of staff in a particular faculty or department, for example if the supervisor has never taught the student or is very busy. Crucially, all faculties in UPM are different; this applies to their expectations, their deadlines, and their staff. In this paper, undergraduate research project/theses will find the basics of what it should be able to expect from an effective supervisor.

How to supervise undergraduate research/theses effectively is a central concern for all research supervisors. Much effort has gone into trying to identify and distil what makes a good supervisor and hence what is good, best or even excellent supervision practice (http://www.edgehill.ac.uk/Research/Degree/ProspStu2.htm). Supervisors in universities have particular concerns about how best to motivate students effectively to take responsibility for their own research learning. 
There is consensus that effective university supervisors are self-reflective and strive always to improve their supervising practice to promote student learning research. To ensure positive research experiences for undergraduate students, supervisors must be effective in their supervising techniques, disciplinary knowledge and expertise. There is no single, definitive answer as to what precisely comprises effective supervision of undergraduate research/theses; rather it is a concept and set of practices constantly under review within a scholarship of supervision and by individual supervisors as reflexive practitioners (http://www.lass.soton.ac.uk/students/researchskills/Research_Topic/crt_05.htm). There is always scope to improve ways of effective supervising, not just by individuals in their own practice, but by communicating these steps to greater effectiveness in ways which mean they can be shared with and adopted by other supervisors. Given the agenda of widening participation in Malaysian higher education, students increasingly do not arrive at university with the skills needed to be effective junior researchers. They may not always take full advantage of the research opportunities presented for many reasons. While it is tempting to label students as lazy, unmotivated, or irresponsible they may in fact be daunted and overwhelmed by the demands of what is expected of them as students at a higher level so they fail or do not fulfill their potential. For most students, this represents the biggest single piece of academic or little scientific work they have had to undertake and is considered the pinnacle of their undergraduate studies. This paper therefore details a piece of research to identify and implement better and more effective ways for supervisors to help students take responsibility for carrying out independent "mini" scientific research project/theses.

\section{Definition of Undergraduate Research}

Across UPM alone, there are many differing definitions and conceptions relating to the undergraduate student research project or theses/dissertation (these terms are used interchangeably although distinctions may be drawn between them, particularly as they will mean different things in different disciplines/courses). It can be a piece of work seen as the culmination of the student's experience; the main integrating activity of the various taught and learned aspects of the course; allows the student to develop initiative and specialist interests; involves the student in investigative tasks and requires the student to draw upon knowledge and experience gained in the preceding years of the course; tests a student's ability to plan and carry out a sustained piece of work by integrating and extending previous studies; gives the student an opportunity to develop and demonstrate skill in identifying, carrying out and writing up a discrete piece of research using academic concepts, theoretical insights and practical abilities acquired on the course; provides a training in research methods and opportunity to undertake sustained, independent, high-level work, which has intellectual credibility. It is important to distinguish between the terms "academic report" and "theses/dissertation". If a forestry science undergraduate undertakes a project and this will normally lead to the production of a written academic report for a 6 credit hours, this may be referred to as a dissertation or theses. Often a project will involve the student in the collection of primary data but this may not always be the case and it may be possible for a report (4 credit hours) to be submitted based on secondary data only.

\section{Supervisor Expectations and Student Responsibilities}

\subsection{Supervisor}

Before any supervisor agrees to supervise undergraduate student project/theses, it is important that the supervisor must understand the faculty/university regulations and requirements regarding the scheme under which the project is taking place. The supervisor needs to know the safety regulations pertinent to the project and support services available for the student. The supervisor must have the time and other resources available to see the project to completion, including funding provision and assistance if appropriate. A strategy for modification must be prepared in the event of major or unforeseen difficulties occur through the process of the supervision. As an effective undergraduate supervisor, there is also the need to identify other faculty members who may be involved with the project and clarified their roles and responsibilities. A supervisor may need to introduce the student to others who will be involved and arranged the location or laboratory space for the student. The supervisor should agree with the student the direction and extent of the research project/theses and the responsibilities that both student-supervisor have towards it. The supervisor's accessibility and routes of contact such as scheduled weekly meetings, open-door office policy, mobile telephone, short messaging system and e-mail contacts need to be equally agreed with the students that the supervisor intends to supervise. A timetable must be set with the student for the stages of the project with agreed milestones and deadlines including a feedback process to keep the student informed about the progress. It is important that the supervisor discuss with the student any requirements for generic skills or additional training like electronic bibliographic databases, statistical methods, and specific laboratory techniques. During the supervision process, the supervisor needs to maintain an agreed time commitment to the student and the project by organizing regular meetings with the student, keeping a record of meetings and of progress of the project and the development of the student in the log book. Reading and responding to the student's written work in an agreed manner and within reasonable time (less than two days after student's submission) by the supervisor must be done in addition to providing regular feedback through e-mails to the student as to their progress. Supervisors must encourage the students to have ownership of their projects/thesis and take responsibility for its execution. Where necessary, an effective supervisor must respond to changes in the need for 
supervision as the student develops by providing effective and appropriate referral to support services, while maintaining confidentiality. The supervisor must be also familiar with the regulations for formal assessment and supporting the student in their preparations for achieving the best grade possible. It is critical that following the formal final project/theses presentation assessment, the supervisor should provide timely, accurate and constructive feedback for the student.

In general, the primary function of the supervisor is to maintain overall, general guidance of the project and to provide a critical and rational sounding board for student ideas. The exact nature and definition of supervisory responsibilities will to some extent depend on the nature of the project; the level and duration of the project; whether projects are supervisor/faculty generated and allocated or student generated and self-selected. The following is not exhaustive or prescriptive, but identifies key functions expected of the supervisor and should be adapted, as appropriate at Faculty level: (a) Assist the student to clarify the topic; to be clearly focused and not over-ambitious; advise the student on the viability of ideas; help with formulating ideas and hypotheses, (b) Direct the student to relevant areas of information, literature sources and specialized internal/external help; require students to produce drafts of sections or chapters of the academic report/theses, (c) Advise on appropriate methodologies/techniques and on consistent referencing style and the plagiarism issues; offer feedback on student's draft which student can then revise; about the organization of student's report/theses into sections or chapters; about matters of presentation, such as the title page, contents page, pagination, footnoting and references, (d) Maintain regular supervisory contact in accordance with faculty policy, (e) Regularly monitor the student's work where supervisors should keep a written log (required by ISO MS 9001:2000) of the opportunities for formal contact offered to students and the actual occurrences of formal contact, (e) Encourage students to keep a written record of all supervisory contact/support noting key points of discussion, (f) Assist the student in managing the timetable of the project, and identifying when problems are liable to be encountered and how they might be tackled, (g) Ensure the student is made aware of inadequate progress, standards of work below the expected level or any assessments which do not reach the required standard - consistently unsatisfactory progress should be made known to the student in writing, (h) Read and comment on drafts of the thesis, where this is requested by the student and return such work with constructive criticism in reasonable time. Supervisors should not be correcting spelling mistakes and effectively editing the thesis/dissertation. Students requiring assistance with this aspect of their work should be encouraged to seek appropriate assistance, and (i) Inform Faculty's Undergraduate Project Coordinator/Deputy Dean (Academic \& International) of any difficulties that are arising.

The theses supervisor should be frequently there in the office/lab to supervise the student work in progress. The official allocation of time for this work will vary from respective supervisors and faculty. However, it is important for the student to make a clear agreement with the supervisor about how supervision will occur. Meetings in the absence of any written work being completed are not generally an effective use of time, as students are wasting their allocated hours. If students have a question to ask or a point to check, then an e-mail will usually suffice. On the other hand, writing a good chunk of material and submitting it before a supervisory meeting means that the supervisor will have had the opportunity to read and comment upon it. It is often a useful idea to arrange to have some time as soon as possible after a supervision session so that students can follow up on the comments. Successful students have also found that it is helpful at the end of each supervision session to plan out clearly the next stage of work and the target dates. If the student works closely with the supervisor in this way, confidence can be build up and that the final work will be guaranteed of a satisfactory standard. Effective supervision may also enable the supervisor to identify where expertise in the department/faculty may be available to support the student work, beyond the supervisor themselves. It is important to remember that the academic report/theses needs to represent a body of individual study and research which is fit for its purpose but which, as a document, also demonstrates internal and intellectual congruence. Poorly conducted research is always unethical and the study must demonstrate that it conforms to the requirements of the governance. But remember - the supervisor's duty is to guide the student so that student can produce the best effort, and not to assist with continual revision until the dissertation has acquired a certain grade that the student may have as a target. Thus, the supervisor's approval of the student's progress cannot be taken to imply any particular grade or classification. The student should not request this of the supervisor at any stage of the project/dissertation module. It should be noted and stressed that the research project/dissertation is the student's responsibility and should represent the student's work; not that of the supervisor. Undergraduate students are expected to work independently and to present academic report/theses at the end of the year.

In some instances, the supervisory mechanism operating at a Faculty level may require a second supervisor. For example, this may occur where a student's project /theses encompasses more than one discipline/subject where input of more than one member of staff is required in order to give sufficient coverage of the project topic. Some Faculties, as a matter of policy, operate this double supervisory mechanism, particularly for dissertations where one supervisor will provide subject expertise and the second supervisor might provide more input in relation to methodologies/techniques and supervision per se. The probable functions expected of the second supervisor which should be adapted, as appropriate, at Faculty level includes availability for periodic consultation in relation to aspects of the project, which 
may be outside the expertise of the principal supervisor, provide support and encouragement to the student throughout the period of the project, an alternative view for student ideas and hypotheses, where appropriate and support for the principal supervisor in case of absence, and finally assist in assessment of the project, where applicable.

\subsection{Student}

The prime responsibility for the management of the project lies with the student who must maintain dialogue between $\mathrm{him} / \mathrm{her}$ self and the supervisor. Before the student begins, one must undertake sufficient background reading to prepare for the project (seeking advice from supervisor if necessary). The student needs to familiarize with regulations and requirements regarding the scheme under which the project is taking place. The student must commit the necessary time required and what skills required to carry out the final year project/theses. The student needs to agree the direction and extent of the research project with the respective supervisor and the responsibilities that each of the student has towards it. The student must agree on the accessibility of the supervisor and routes of contact (e.g. scheduled weekly meetings, open-door policy, telephone and e-mail contacts etc). A timetable should be set with the supervisor for the stages of the project, with agreed milestones and deadlines. A feedback process with the supervisor to keep student informed about the progress needs to be arranged. Students have to request the supervisor for a transparent system of record-keeping relating to the project, bearing in mind any data protection issues if data from human subjects is to be collected. Where requirements for generic skills or additional training (e.g. bibliographic databases, statistical methods, specific laboratory techniques) are required, it may be discussed with the supervisor.

During the project, students are required to attend and participate in activities relating to the project as discussed in advance, and ensuring that milestones and deadlines are met on time. Students must be working effectively and seeking advice whenever necessary using the facilities and resources appropriately provided by the Faculty. It is highly commended that students are to meet with respective supervisors as agreed, and recording and reflecting on the outcomes of the meetings in the log book. It is important that the students are aware of available sources of support and how to access them. The students must be familiar with the regulations for formal assessment so that students can ensure these are met. After the project completion, it is expected that the students should be able to provide thoughtful and constructive feedback on their experiences to respective supervisors, and (while maintaining confidentiality) to the Faculty. Students should be able to reflect on their project but may also be able to identify benefits that are not easy to quantify, such as increase in confidence, degree of independence and ability for self-teaching. The students are expected to have a broader skills base especially in communication skills, IT, writing and presentation skills.

The responsibility for the work submitted is entirely that of the student. The student should manage the relationship with his/her supervisor, keeping in regular contact with him/her according to faculty's policy. The student needs to discuss with the supervisor the type of guidance and comment that are most helpful while agree a schedule of meetings with the supervisor for reports/briefing on progress, ensuring the agreed schedule is adhered to and any deadlines met. Initiative must be taken by the student to discuss any problems with the project work and/or its supervision so that these can be resolved as soon as possible. A proper diary of work conducted related to the project has to be kept whenever the student meet or discuss with the supervisor. This would include: notes on discussions/correspondence with supervisor and any other internal/external specialists; literature read and comments; ideas/designs; results of tests/experiments; problems found and solutions; equipment details and settings; project costs; resources used; diagrams, plans, sketches, photographs; raw data; floppy disks etc. The students are to submit the research project/thesis in the specified format, on time and according to the Faculty's mechanism for handing-in project work and submit for any other assessments as required by course regulations.

\subsection{The Faculty Management}

The Faculty on the other hand should also provide necessary support services for staff and students to ensure adherence to equal opportunities legislation and health/safety regulations during the undertakings of final year project/theses. The Faculty, in particular the Deputy Dean (Academic \& International) must record and monitor progress of students and projects involved in the scheme and provide clear rules and regulations for the formal assessment of the project, which should be reliable, defensible and transparent to all students. The Faculty Management Team should bear the following points in mind when coordinating and managing supervisory input of undergraduate projects/theses: (a) Flexibility in spread of supervision - faculty should have flexibility to determine for each project/dissertation, how best the overall time and supervisors could be allocated. As the nature of theses/projects varies considerably in different disciplines of forestry science and technology, and front and end loading in terms of supervisory input is often the norm, then it would be too prescriptive to identify the spread of timing of supervision, (b) Different thresholds for different modes of undergraduate CGPA delivery - should there be a different level of supervisory support for excellent standing (CGPA $>3.5$ ) students undertaking projects/theses? However, there may be a case for having a higher minimum threshold as students that are below 2.5 CGPA may be less likely to benefit from the "informal" supervision that students with above 3.0 CGPA probably do benefit from. Weighed against this, should be any input that below 2.5 CGPA students might be more likely to receive supervisor's personal telephone and email contacts? This begs the question, what form of contact 
should be counted as supervisory input - face-to-face, email, mobile telephone, or even house tutorials, etc?, (c) Different disciplines - do different disciplines warrant a different level of input, for example the nature of supervision for design based projects such as Forest Engineering Survey is very different from the supervision of say, Forest Management based subjects. Based on the information provided by the survey, it does not appear to be an issue but may be worthy of further debate/discussion within the Faculty or even University, (d) Whose input is included as minimum input - where there is additional input from industrialists/laboratory supervisors etc, how should this impact, if at all, on decisions relating to levels of minimum supervisory input? Are faculty members just determining the minimum level of academic supervisory input regardless of these other input sources? Similarly, what, if any, distinction between first supervisor and second supervisor level of input should be made and (e) Excessive supervision - As projects/dissertations should represent an equivalent degree of challenge, the level of supervision required by a student should reflect student ability with regard to this aspect of the course. Faculty might want to take excessive supervision into account when determining the overall performance of the student.

\section{Survey Data Collection}

The author has existed in various forms for some years and, as well as working together on undergraduate research projects/theses, is dedicated to delivering high quality supervising of qualitative and quantitative forest engineering and survey research methods, encompassing methods of data collection such as semi-structured interviewing, focus groups of final year undergraduates, diaries and archive data interviewing. In particular, the author has been concerned that undergraduate forestry students doing quantitative research projects in their final year feel adequately prepared for this important task. The author began to wonder how colleagues in other faculties supervised students about their projects. In brief, the author wanted to develop the Final Year BS Forestry Theses Guideline that had already been drafted in the Faculty by adopting the UPM School of Graduate Studies (SGS) mainly by listening to colleagues and identifying areas of best practice. In addition, the author wanted to hear students talk about their experiences of supervision and their recommendations for improving quality. The author's aim was to produce a set of guidelines that could be used by colleagues across UPM with the following key questions namely, what makes a good undergraduate Bachelor of Forestry Science project/theses by giving examples of good and bad work, which research methods are most appropriate for undergraduate level forestry science and technology projects and why? How much data should students collect at this level, and what are the factors which mediate this question? What are the key ethical issues generated by undergraduate research project/thesis, and how can these is addressed?

The author has also obtained some feedback from the 2005-6 cohort of undergraduate forestry science students' $(\mathrm{n}=15)$ supervision experiences in the Faculty of Forestry UPM on their experience of conducting their final year undergraduate research/thesis project as part of a larger study on undergraduate research supervision at the Faculty of Forestry, UPM. A qualitative inquiry of these students' perceptions, employing face-to-face interviews was conducted. However, the questionnaire approach was also used where some final year students working on their research project/theses were invited to complete an open-ended questionnaire which included items on prior training in research/thesis methods, percent satisfaction with project supervision, frequency of contact, ease of access, good working relationship, support and encouragement, comparisons with quantitative/qualitative projects and costs and benefits of doing a final year research project/thesis.

\section{Student Perceptions of the Supervisor's Role}

This section presents the results of a survey of undergraduates' perceptions of their supervision as they undertake their final year research student's project in the Faculty of Forestry, UPM. Students reported that only a selective few of their supervisors were supportive and sympathetic to their needs. The majority of supervisors did not adopt the role of resource person, directing students to references and contacts, discussing ideas and work undertaken. Most students had considerable freedom in the conduct of their work. They were given responsibility for many decisions concerning their research: most, for instance, chose their own research topic and supervisor and most determined the pace at which they worked. They appeared to cope well with the autonomous role of researcher but some commented on difficulties. The non-directive role adopted by supervisors enabled students to develop less skills of working on their own. Though the majority of students were given considerable freedom in their research, the results of the survey indicated some differences between students. Forest engineering based students had greater responsibility for decision making than their forest recreation or management counterparts.

It became apparent from the survey that, while the majority of the undergraduate students appear to have achieved such a working relationship with their supervisors, for those who have not, it becomes a major stumbling block. Some students were slightly less satisfied with the quality of supervision obtained from their supervisors in the Faculty. Majority of the students initially asked their supervisor for advice on choice of topic and reading materials. Not too many students talked to their supervisors because of less regular meetings held by the student-supervisor. Draft chapters were not showed accordingly to the supervisor as soon as the students have them. Students did not give their supervisors time to read, think and feed back. It is to be noted that the majority of the supervisors offer constructive 
criticisms of the undergraduate work: that is why he/she is there. It is not a criticism of the student, or of the student's ability. Do not be shy or embarrassed by this. The student's personal supervisor is a resource: use that resource to the student advantage. Students must ask their supervisors questions, about methodology, theory, or anything else that may occur. Students are not expected to be an instant expert and it is a well known fact that it is the supervisor's job to train them. Supervisors must help students, but they not do the student work for the student. Supervisors can only work with what the students bring them. In this study, a few supervisors were interviewed and talked about their experiences of supervising undergraduate academic project/theses. Many described the academic report/theses as a 'journey', seeing their role as facilitating that 'journey' and making their students' plans achievable, rather than directing the student to take a particular route. The role of the supervisor is essentially to try and help make the student project realizable, rather than impose something on them. Remember that the student research project is theirs. The supervisor is just there to guide, not to tell the student exactly what to do. Note that only one or two supervisors normally have a timetabled allowance for theses supervision to make sure the student take advantage of it. The student is reminded to take the initiative in approaching the supervisor and do not wait to be asked. The student should make a point of contacting respective supervisor at least once a month and not let things drift. The student can be given assistance in understanding specific aspects of methodological technique and general guidance on, for instance, construction of a questionnaire. All supervisors are expected to read the first drafts of theses chapters in some detail but to comment on later and final versions only in a general sense. There is a clear disparity of resources/facilities between the faculty and undergraduate students. Majority of the undergraduates rated faculty facilities as less than acceptable. From the comments received, the chief issues are financial support, space, printing, WIFI internet and printing facilities.

\section{Good Practice and Strategic Coordination in the Supervision of Undergraduate Research Projects}

These guidelines are not regulatory and should be seen as an accompaniment to the relevant Faculty's Undergraduate Research Handbook. The aim is to provide a good practice guideline for supervision of undergraduate academic projects and theses/dissertations to ensure consistency of approach for staff and students across the Faculty of Forestry and the other faculties in UPM. The key functions are identified which should be fulfilled in terms of the supervisory process. The Faculty should determine the most appropriate mechanisms for fulfilling these functions. The guidelines relate to undergraduate research/theses, although it is acknowledged that the supervisory function at these two levels will be different, in particular the supervisory function for theses work is likely to be of "heavier" emphasis than that for the undergraduate academic project report work. The three key elements identified for a successful and effective supervision of undergraduate student academic project/theses are (i) clarity of responsibilities for both the supervisor and the student where both parties must take responsibility for ensuring that satisfactory progress is being achieved throughout the entire duration of the project, (ii) co-ordination of the supervisory process at Faculty level, where it is important that supervisory practice is consistent within the entire duration of undergraduate research course, and (iii) record keeping of all supervisory input/support by both staff and students. This information is particularly significant where, as part of the project/theses assessment, the student's performance is evaluated in terms of their input into the research process, or in the case of a student appeal. Students should be encouraged to write up, in an agreed format, the outcomes of any supervisory contact. It is very important that every student must receive equitable qualitative standards of supervision from all Faculty members. There have been informal reports by undergraduate students in the Faculty of Forestry UPM that they have not been receiving quality and effective supervision and guidance from their respective supervisors. This has been proven over the past few years when some final year students had to repeat their final year project presentation because of major technical weaknesses in their academic reports/theses. In-house Faculty practice should then determine what quantitative/qualitative levels of supervision are used as standard. The quantity of supervision/assistance required is important in that it may be taken into account in assessing student performance.

It is important that at the faculty level, there is a mechanism for coordinating and administering supervision on a daily basis and a mechanism for maintaining a strategic overview of project/dissertation practice. The primary function of the Final Year Project Coordinator is to ensure that the project/dissertation module is efficiently and effectively coordinated on a day-to-day basis, if possible. The key activities expected within this function includes: (a) Organization and administration concerning student projects, (b) Liaising with supervisors and resolving, where possible, any individual difficulties, (c) Resolving difficulties such as major equipment breakdown, (d) Identify suitable topics for projects, (e) Approve project outline proposals/timetables prior to the start of projects, (f) Resolve any administrative problems and issues relating to the degree of difficulty/feasibility of project proposals, particularly in terms of resources available, $(\mathrm{g})$ Authorize any major change in project design/topic, if any (h) Allocate students to projects and supervisors in an acceptable and fair manner, and (i) Ensure appointment of supervisors at the earliest possible opportunity, appropriate, adequate and equitable supervision and ensure appropriate external support/supervision is readily available when sufficient expertise within the faculty cannot be found.

\section{Conclusion}

Effective supervision is a key element in successfully completing the transition from undergraduate to postgraduate 
cycles. Supervision can be challenging for both supervisors and students. It is useful to review practice and try new techniques. This study indicates that good communication is fundamental to supervision. It plays an important role in building trust and goodwill, and helps to prevent misunderstandings between supervisor and student. Good communication will ensure the effectiveness and enjoyment of supervision as well as the progress of the student's research. In the early stages of supervision especially, regular meetings will help to establish effective communication. Not all Forestry Faculty students are "at risk" of course, but many seem to be exposed to unhealthy and unnecessary stress and risk working on their academic project report/theses with non-effective supervisions by some faculty members. In the author's view, the Faculty has still a long way to go in meeting these responsibilities if genuine high quality graduates are the targets for postgraduate's cycles. The author believes that the quality of undergraduate student supervision begins to deteriorate with the premise that UPM's Key Performance Index (KPI) only emphasizes on postgraduate supervision. It is to the assessment of the author that at least some of the current supervision practices in the Forestry Faculty are less than effective for the students and that there are ways and means for providing more effective supervision practices for these young successful researchers of the future. However, the author is pessimistic about improvement being achieved by a well-articulated list of $d o$ 's and don'ts for students, supervisors and the faculty management. It is hoped that the lessons learnt from the Faculty of Forestry, UPM may be of interest and even use to others in UPM and elsewhere.

\section{References}

Expectations of students and supervisors:http://www.edgehill.ac.uk/Research/Degree/ProspStu2.htm

You and your supervisor: http://www.lass.soton.ac.uk/students/researchskills/Research_Topic/crt_05.htm 